\title{
Teleconsulta en Odontología para paciente con síndrome de Down durante la pandemia por COVID-19: reporte de caso
}

\author{
Adrián Rojano-Rodríguez, ${ }^{1}$ (1) Andrés Rey-Arrieta, ${ }^{2}$ (10 Shyrley Díaz-Cardenas. ${ }^{3}$ (1)
}

\begin{abstract}
Resumen: En situaciones de crisis sanitarias como la pandemia COVID-19, suele limitarse el acceso a servicios de salud oral, especialmente en pacientes con condiciones especiales que requieren intervenciones clínicas, controles y seguimientos de tratamientos nuevos o ya programados. La Teleconsulta en odontología representa un recurso valioso en salud oral para pacientes que presenten dificultades al acceso de la atención. El presente artículo reporta el caso clínico de una paciente de 8 años con síndrome de Down, atendida mediante teleconsulta en odontología. La intervención se planeó en tres etapas: Etapa 1. Valoración riesgo familiar y oral, Etapa 2. Orientación en salud oral y familiar y Etapa 3. Seguimiento de actividades. En esta intervención, se adaptaron tres instrumentos y se aplicó un cuarto para la recolección de la información. El abordaje en teleodontología con esta paciente tuvo una duración de 3 meses, con consultas semanales usando la aplicación de WhatsApp. Se identificaron factores de riesgo para la salud oral de la paciente y su familia, como el síndrome de Down, presencia de biofilm dental, alto consumo de azúcar, baja frecuencia del cepillado oral y limitada fuente de ingresos económicos a causa de la pandemia COVID-19 entre otros. A partir del seguimiento realizado por teleodontología, se logró aceptación de la orientación educativa para disminuir los factores de riesgo encontrados d en la paciente y su núcleo familiar.
\end{abstract}

Palabras clave: tecnología de la información, teleconsulta, teleodontología, atención odontológica, síndrome de Down, COVID-19.

\section{Teleconsulta em Odontología para um paciente com síndrome de Down durante a pandemia da COVID-19: Relato de Caso}

\begin{abstract}
Resumo: Em situações de crise de saúde como a pandemia COVID-19, o acesso aos serviços de saúde oral é freqüentemente limitado, especialmente para pacientes com condições especiais que requerem intervenções clínicas, monitoramento e acompanhamento de tratamentos novos ou planejados. A teleorientação em odontologia representa um recurso valioso em saúde oral para pacientes que apresentam dificuldades no acesso aos cuidados. Este artigo relata o caso clínico de um paciente de 8 anos com síndrome de Down, atendido por meio de teleconsulta em odontologia. A intervenção foi planejada em três etapas: Etapa 1. Avaliação de risco familiar e oral, Etapa 2. Orientação em saúde oral e familiar e Etapa 3: Acompanhamento das atividades. Nesta intervenção, três instrumentos foram adaptados e um quarto foi aplicado para a coleta de dados. A abordagem teleodontológica com este paciente durou 3 meses, com consultas semanais utilizando o aplicativo WhatsApp. Foram identificados fatores de risco para a saúde oral da paciente e sua família, como a síndrome de Down, presença de biofilme dental, alto consumo de açúcar, baixa freqüência de escovação oral e fonte limitada de renda devido à pandemia COVID-19, entre outros. Com base no acompanhamento realizado pela teleodontologia, a aceitação da orientação educacional foi alcançada a fim de reduzir os fatores de risco encontrados pelo paciente e sua família.
\end{abstract}

Palabra-chave: tecnologia da informação, teleorientação, teleodontologia, assistência odontológica, síndrome de Down, COVID-19

\footnotetext{
1 Estudiante de odontología X semestre. Facultad de Odontología Universidad de Cartagena. Cartagena de Indias, Colombia. arojanor@unicartagena.edu.co

2 Estudiante de odontología X semestre. Facultad de Odontología Universidad de Cartagena. Cartagena de Indias, Colombia. areya@unicartagena.edu.co

3 Odontóloga. Magister en Salud Pública. Docente titular Facultad de Odontología Universidad de Cartagena. Cartagena de Indias, Colombia. sdiazc@unicartagena.edu.co
} 


\section{Teleconsulting in dentistry for a Down syndrome patient during the COVID-19 pandemic: a case report}

Abstract: In health crisis situations such as the COVID-19 pandemic, access to oral health services is often limited, especially in patients with special conditions that require clinical interventions, controls and follow-up of new or already scheduled treatments. Teleconsultation in dentistry represents a valuable resource in oral health for patients who present difficulties in accessing care. This article reports the clinical case of an 8-year-old patient with Down syndrome, attended by means of teleconsultation in dentistry. The intervention was planned in three stages: Stage 1. Oral and family risk assessment Stage 2. Orientation in oral and family health and Stage 3: Followup of activities. In this intervention, three instruments were adapted and a fourth was applied for data collection. The teleconsulta approach with this patient lasted 3 months, with weekly consultations using the WhatsApp application. Risk factors for the oral health of the patient and her family were identified, such as Down syndrome, presence of dental biofilm, high sugar consumption, low frequency of oral brushing and limited source of income due to the COVID-19 pandemic, among others. From the follow-up carried out by teleodentistry, acceptance of the educational orientation was achieved in order to reduce the risk factors found by the patient and her family.

Keywords: information technology, teleconsulting; teledentistry, dental care, Down syndrome, COVID-19.

\section{Introducción}

A finales del 2019, médicos en Wuhan, China, descubrieron un nuevo coronavirus (SARS-CoV-2) el cual causaba una enfermedad altamente contagiosa caracterizada por neumonía, pérdida del gusto y del olfato, fiebre, tos seca, cansancio y cefalea. ${ }^{1}$ Esta enfermedad terminó extendiéndose rápidamente por todo el mundo, convirtiéndose en una pandemia global y en una emergencia de salud pública de interés internacional. ${ }^{2}$ Debido a las formas de contagio de la enfermedad, algunos entornos han sido identificados como de más alto riesgo: consultorios, clínicas y universidades.

La atención a nivel odontológico con la utilización de equipos que generan aerosoles $^{3}$ producen un aumento del riesgo de infección cruzada entre pacientes y equipo profesional (odontólogo y auxiliares). ${ }^{4}$ Múltiples lugares donde se brinda atención odontológica se vieron en la necesidad de instaurar con urgencia estrictos protocolos de bioseguridad para el control de infecciones ${ }^{5}$ ante la pandemia. La mayoría de los procedimientos odontológicos de rutina en todo el mundo suspendieron su atención y solo realizaron cirugías y procedimientos dentales de emergencia. ${ }^{6}$

A lo largo de los años, la Teleodontología ${ }^{7}$ (TO) a través de la Teleconsulta ${ }^{8}$ ha demostrado ser beneficiosa para brindar consultas y establecer un plan de tratamiento, direccionado principalmente a mantener y proteger la salud oral. ${ }^{9}$ Actualmente, en ciudades sudamericanas como Sao Paulo ${ }^{10}$ y Minas Gerais en Brasil, ${ }^{11}$ la TO está siendo utilizada como herramienta para propiciar la atención durante la pandemia de COVID-19, permitiendo la reducción del contacto físico entre odontólogos y pacientes y por tanto, se evita la propagación del virus.

La incorporación de la TO a la práctica 
odontológica de rutina durante la pandemia del COVID-19, propició cambios en la atención de pacientes, ya que desde la comodidad de los hogares se logró llegar a aquellas zonas donde se existían poblaciones vulnerables, y algunas, además presentaban condiciones especiales. ${ }^{10,11}$

Dentro de esas poblaciones se encuentran los pacientes con síndrome de Down (SD), cuya prevalencia global es de 10 por cada 10.000 nacimientos vivos, según la Organización Mundial de la Salud. ${ }^{12}$ En Colombia, según el último censo del 2005 se estableció una tasa de mil nacimientos, siendo el $1,72 \%$ de niños que nacieron con SD. ${ }^{13}$ El SD no sólo presenta alteraciones generales como hipotonía muscular, cuello corto, perfil facial plano, hiperlaxitud ${ }^{14}$ sino también, a nivel oral. Se precisan estrictos seguimientos para el control de gingivitis, mal posición dental y de la anatomía de fosas y fisuras profundas. ${ }^{15}$

Los pacientes con SD frecuentemente son atendidos en instituciones académicas que ofrecen apoyo y soporte para el manejo integral de sus tratamientos. Esto es realizado bajo la modalidad de convenios docencia-servicio como es el caso de la Facultad de Odontología de la Universidad de Cartagena, que venía ofreciendo atención en salud oral a este tipo de pacientes a través de prácticas presenciales con estudiantes en una institución privada. ${ }^{16}$

Los estilos de vida adquiridos durante la pandemia, tales como las alteraciones a nivel de la dieta, además de la falta de atención odontológica, control y seguimiento presencial podrían hacer más vulnerables a los pacientes con SD, para el desarrollo de caries y otras afecciones orales. En junio del 2020, tres meses después de declarada la pandemia, se publicó el protocolo de atención que incorporó el uso de la TO y su aplicación en la odontopediatría durante la pandemia COVID-19,8 pero mientras tanto, se diseñaron e implementaron intervenciones aisladas como las realizadas en este caso, para continuar ofreciendo atención en salud oral.

Este artículo se refiere al reporte de un caso de una paciente con SD que fue atendida a partir de una intervención, diseñada un tiempo anterior a la publicación del Protocolo ALOP, ${ }^{8}$ usando la TO, se tiene como objetivo aportar más evidencia clínica y práctica acerca de su uso, como modalidad de atención, ya que la TO fue implementada exitosamente en diferentes espacios odontológicos, tanto públicos como privados, para la atención de pacientes en la Universidad. 5,10

\section{Metodología}

Se realizó una intervención con TO, a un grupo de familias de niños con SD (160 familias), que concurrieron al Instituto de Rehabilitación El Rosario. Esta institución es de carácter civil y sin fines de lucro, dedicada al mejoramiento de la calidad de vida de la infancia, adolescencia y de los adultos jóvenes, con énfasis en personas que tienen condición de discapacidad cognitiva, de la ciudad de Cartagena de Indias-Colombia; la institución tiene hasta el momento convenio docente asistencial con el programa de Odontología de la Universidad de Cartagena desde hace más de 10 años. 
La intervención e instrumentos utilizados fue planteada y consensuada un mes después de declarada la Pandemia COVID-19 (abril 2020), por un equipo de tres docentes expertos de la Facultad de Odontología, pertenecientes al departamento de Odontología Preventiva y Social y especialistas en Salud Pública, Odontopediatría y Salud Familiar (Katherine Arrieta Vergara, Ketty Ramos Martinez y Shyrley Díaz Cárdenas)

Se realizó una primera reunión virtual con en el personal administrativo y profesional (pedagogos, psicólogos, trabajador social, fisioterapeutas) del Instituto de Rehabilitación El Rosario, el 10/04/2020, con el objetivo de dar a conocer la intervención. A su vez, el Instituto realizó la socialización de la nueva modalidad de atención en salud oral a las familias beneficiarias del programa de Odontología.

La gran mayoría de las familias beneficiarias que concurren a la institución pertenecen a estratos socioeconómicos bajos, con escasos ingresos, factores que podrían representar una dificultad para la ejecución de la TO, al no poder disponer de los elementos necesarios para su realización, como equipos de comunicación y servicios de internet.

Para conocer estos aspectos y hacer viable la ejecución de la intervención, se realizó una caracterización de los dispositivos electrónicos y disponibilidad de datos de internet que tenían las familias mencionadas, para luego identificar cuáles de esas familias podían acceder al servicio en esta modalidad. Sin embargo, se acordó con los estudiantes de Odontología un apoyo a las familias que presentaban dificultades, a través de recargas de datos de internet (realizadas con recursos propios de los estudiantes intervinientes), con el ánimo de realizar una labor social más allá del cumplimiento de sus obligaciones académicas.

En una segunda reunión, el 13/04/2020, con las familias que se mostraban interesadas en participar (15 familias),el equipo responsable de la intervención (6 Docentes y 30 estudiantes) les presentó la nueva modalidad de atención en salud oral, ya que antes se realizaba de manera presencial; la misma se llevaría a cabo mediante el apoyo de herramientas tecnológicas virtuales como llamadas telefónicas y video llamadas, utilizando la aplicación WhatsApp o plataformas como Google Meet, durante los encuentros sincrónicos. Las familias fueron asignadas al azar, una familia por cada dos estudiantes de décimo semestre.

Se programó una tercera reunión, el 14/04/2020 sincrónica (videollamada) por parte de los docentes encargados a través de la plataforma Google Meet cuyo objetivo era la presentación de los dos estudiantes asignados a la familia que corresponde al caso que hace referencia este trabajo.

Para la realización de este estudio, se tuvo en cuenta los criterios éticos estipulados en la resolución 8430 de 1993 del Ministerio de Protección Social de Colombia ${ }^{17}$ y se siguieron las normas establecidas en la Declaración de Helsinki de 1975.

Se envió el consentimiento informado de forma digital para que la familia lo firme, antes de empezar con este nuevo tipo de atención. Como la paciente y su hermano eran menores de edad, la madre firmó los consentimientos informados de ellos. 
Cuadro 1. Planificación de la Intervención TO en Paciente con Síndrome de Down abril - junio 2020.

\begin{tabular}{|c|c|c|c|c|c|c|c|c|c|c|c|c|}
\hline \multirow{2}{*}{$\begin{array}{l}\text { Mes-Semanas } \\
\text { Etapas } \\
\text { Etapa 1. Valoración del riesgo familiar y oral }\end{array}$} & \multicolumn{3}{|c|}{ Abril } & \multicolumn{4}{|c|}{ Mayo } & \multicolumn{5}{|c|}{ Junio } \\
\hline & 15 & 24 & & & & & & & & & & \\
\hline Etapa 2. Orientación en salud oral y familiar & & & 27 & 04 & 11 & 18 & 25 & 01 & & & & \\
\hline Etapa 3. Seguimiento & & & & & & & & & 08 & 15 & 22 & 29 \\
\hline
\end{tabular}

Para realizar esta intervención, los estudiantes fueron previamente entrenados y capacitados por el equipo de expertos que diseñó la intervención en sus diferentes etapas, a partir de dos encuentros sincrónicos.

Se dividió la intervención en tres etapas: Etapa 1. Valoración del riesgo familiar y oral. Etapa 2. Orientación en salud oral y familiar y la Etapa 3. Seguimiento (Cuadro 1). En cada etapa se utilizaron instrumentos para la recolección de la información. A continuación, se describirán los instrumentos y luego las etapas de intervención.

\section{Reseña de los instrumentos}

Los instrumentos utilizados en esta experiencia para el registro de la información surgieron de la adaptación de otros instrumentos ya empleados en las historias clínicas odontológicas individual y de salud familiar para la atención presencial tanto en el Instituto de Rehabilitación El Rosario, como así también en las instalaciones de la Facultad de Odontología de la Universidad de Cartagena. Por lo tanto, en esta investigación, se tomaron los datos correspondientes de ambas historias clínicas mencionadas, y se los incluyó en los instrumentos definidos para esta TO, con el objetivo de agilizar la atención en esta modalidad.
En la etapa 1 se diligenció el instrumento Valoración del Riesgo Familiar y Oral (Imagen 1) para recolectar variables cuantitativas sociodemográficas y familiares de la paciente: edad, sexo, escolaridad de la paciente y sus padres, estado civil de los padres, número de hijos (sexo, edad) en el hogar, tipo de familia (nuclear, extensa, monoparental), ingresos socioeconómicos mensuales, presencia de hacinamiento según la disposición de número de miembros por cuarto y antecedentes médicos de la paciente y la familia. Se incluyó también, riesgo de contagio por COVID-19 durante las últimas dos semanas anteriores a la entrevista y presencia de otros factores relacionados con el estado de salud general de la familia, la actividad física y presencia de estrés a causa de la Pandemia.

Para recolectar las variables relacionadas con el riesgo oral se estudiaron los registros de las consultas odontológicas realizadas a los miembros de la familia. Se buscó presencia de enfermedades orales sin tratamiento además de la dieta y hábitos de higiene oral. La valoración oral clínica se realizó únicamente a la paciente con SD a través de fotografías intraorales, para estimar su estado de salud oral.

Con las fotografías intraorales obtenidas y videollamada familiar, se diligenció el segundo instrumento utilizado en esta 


\begin{tabular}{|c|c|c|c|c|c|c|c|c|c|c|c|c|c|}
\hline \multicolumn{14}{|c|}{ NOMBRE DEL PACIENTE } \\
\hline \multicolumn{14}{|c|}{ DATOS DE LA FAMILIA } \\
\hline \multicolumn{14}{|c|}{ Apellido de la familia: } \\
\hline \multicolumn{14}{|c|}{ Dirección actual: } \\
\hline \multicolumn{14}{|c|}{ Teléfono } \\
\hline \multicolumn{14}{|c|}{ Teléfono alternativo (familiar o vecino) } \\
\hline \multicolumn{14}{|c|}{ Correo electrónico } \\
\hline \multicolumn{14}{|c|}{ Procedencia } \\
\hline \multicolumn{14}{|c|}{ SEGURIDAD SOCIAL } \\
\hline \multicolumn{4}{|c|}{ Regimen contributivo } & \multicolumn{10}{|c|}{ Regimen subsidiado } \\
\hline \multicolumn{4}{|c|}{ No se encuentra afiliado } & \multicolumn{10}{|l|}{ Otros } \\
\hline \multicolumn{14}{|c|}{ CENSO FAMILIAR } \\
\hline No. & Nombre y apellido & Edad & Sexo & $\begin{array}{l}\text { Parentesco } \\
\text { con el } \\
\text { cabeza de } \\
\text { familia }\end{array}$ & Escolaridad & Ocupación & \begin{tabular}{|l} 
Se encuentra \\
trabajando/ \\
estudiando en \\
la actualidad
\end{tabular} & \begin{tabular}{|l} 
Promedio \\
de ingresos \\
familiares \\
(valor \\
monetario)
\end{tabular} & Hábitos & \begin{tabular}{|l|} 
Última \\
visita al \\
odontólogo
\end{tabular} & \begin{tabular}{|l} 
Enfer- \\
medad \\
presente
\end{tabular} & $\begin{array}{l}\text { Medica- } \\
\text { mentos } \\
\text { que se } \\
\text { están } \\
\text { tomando }\end{array}$ & \begin{tabular}{|l|} 
Algún \\
miembro \\
de la \\
familia ha \\
presen- \\
tado un \\
problema \\
de salud en \\
las últimas \\
2 semanas \\
\end{tabular} \\
\hline \multicolumn{14}{|l|}{1} \\
\hline \multicolumn{14}{|l|}{2} \\
\hline \multicolumn{14}{|l|}{3} \\
\hline \multicolumn{14}{|l|}{4} \\
\hline \multicolumn{14}{|c|}{ AMBIENTE FÍSICO DE LA VIVIENDA } \\
\hline \multicolumn{14}{|c|}{ ¿Vivienda propia o arrendada? } \\
\hline \multicolumn{14}{|c|}{ ¿Cuenta con sala? } \\
\hline \multicolumn{14}{|c|}{ ¿Cuenta con cocina? } \\
\hline \multicolumn{14}{|c|}{ ¿La coccina está ubicada fuera de la sala o de otra área de la casa? } \\
\hline \multicolumn{14}{|c|}{ ¿Cuenta con todos los servicios públicos? } \\
\hline \multicolumn{14}{|c|}{ ¿Cuantos cuartos tiene la vivienda? } \\
\hline \multicolumn{14}{|c|}{ OBSERVACIONES } \\
\hline
\end{tabular}

Imagen 1: Instrumento No. 1 Valoración de Riesgo Familiar y Oral.

misma etapa, el Caries Management by Risk Assessment (CAMBRA) ${ }^{18}$ (Imagen 2), en formato actualizado (2007), para pacientes mayores de 6 años, el cual valoró la combinación de factores relacionados con la incidencia de la enfermedad de caries.

En la etapa 2, se contó con un tercer instrumento con dos formatos: Plan de guías Anticipatorias y la Guía Anticipatoria (Imagen 3 y 4). Cabe aclarar que en el Plan de Guías Anticipatorias se incluyeron las Guías Anticipatorias correspondientes a cada factor de riesgo familiar y oral detectados en la etapa 1.

Las Guías Anticipatorias (son el formato utilizado en el área de salud Familiar de la 


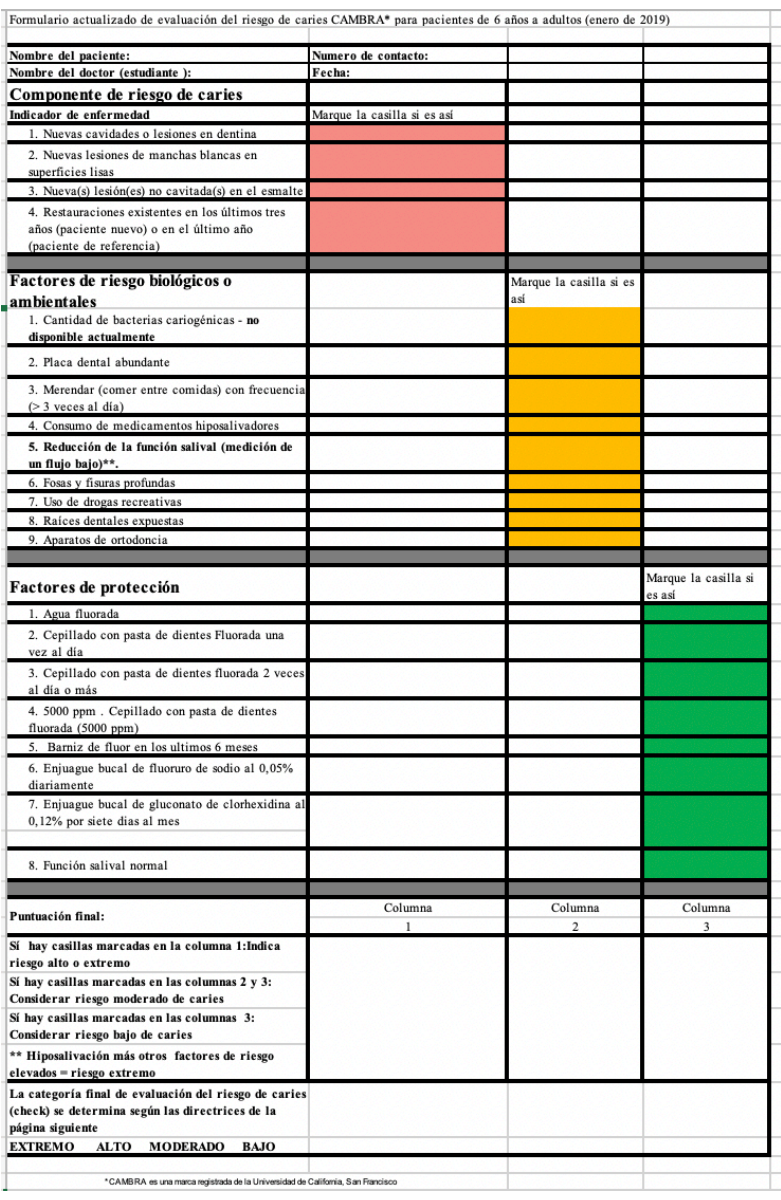

Imagen 2: Instrumento No. 2. Caries Management by Risk Assessment (CAMBRA)
Facultad de Odontología, Universidad de Cartagena) describen conceptos básicos de educación y recomendaciones sobre las crisis normativas que tienen lugar en cada etapa del ciclo vital individual y familiar; ${ }^{19,20}$ son particularmente aplicables en el examen periódico de salud y en grupos expuestos al riesgo, para estimular anticipadamente cambios en el comportamiento, mejorar la adhesión al tratamiento y modificar riesgos de enfermar $y$ de morir. ${ }^{19,20}$

Los contenidos educativos de las Guías Anticipatorias refieren, por ejemplo, a la posibilidad de detectar en la etapa escolar la crisis normativa por vivir en la etapa de la adolescencia o prevenir algún evento o enfermedad como obesidad, hipertensión, accidentes de tránsito, diabetes, violencia intrafamiliar, entre otras. ${ }^{19,20}$

En los contenidos educativos y recomendaciones ofrecidas de cada guía, se incluyen también, los compromisos aceptados por las familias o los pacientes a partir de sus recursos y condiciones. (Imagen 4)

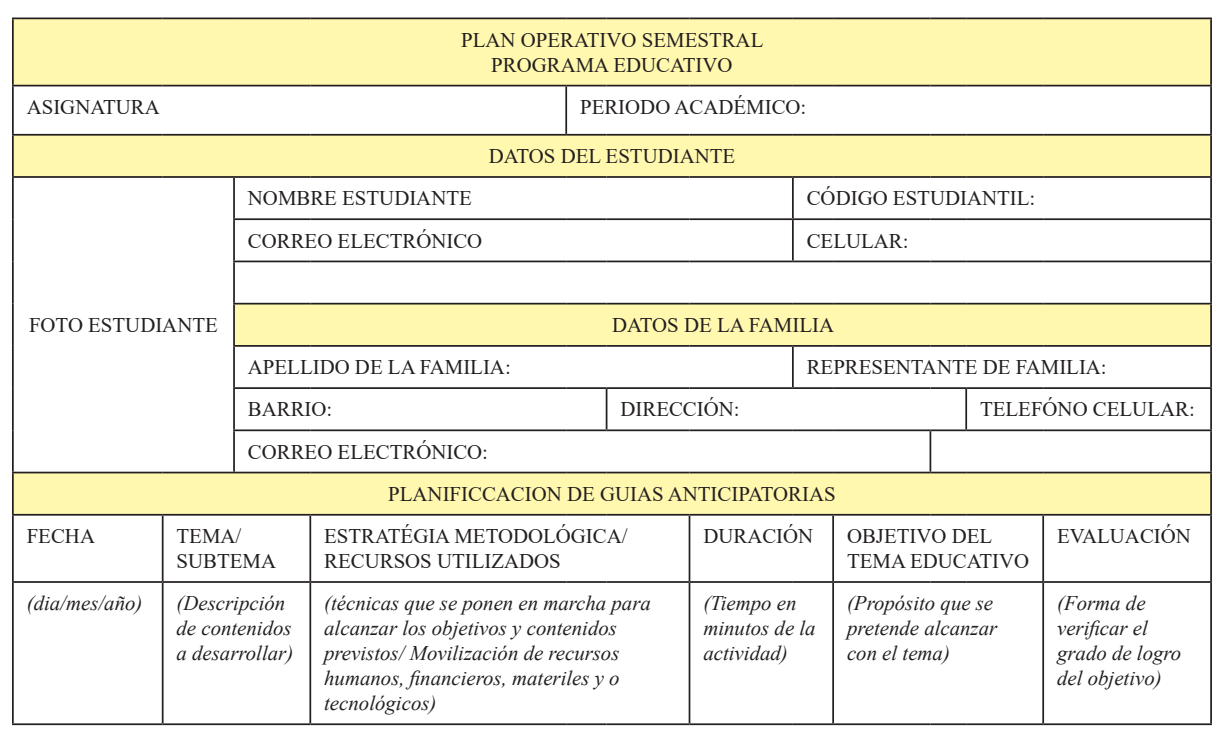

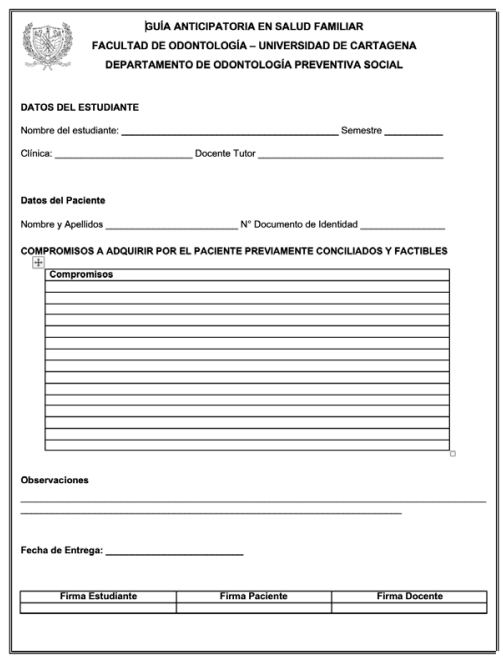

Imagen 3 y 4. Instrumento No.3. Plan de Guías anticipatorias y Formato Guía Anticipatoria 


\begin{tabular}{|c|c|c|c|}
\hline \multicolumn{4}{|c|}{$\begin{array}{l}\text { PLAN OPERATIVO SEMESTRAL } \\
\text { PROGRAMA EDUCATIVO }\end{array}$} \\
\hline \multicolumn{4}{|c|}{ PERIODO ACADÉMICO: } \\
\hline \multicolumn{4}{|c|}{ DATOS DEL ESTUDIANTE } \\
\hline \multirow{6}{*}{ FOTO ESTUDIANTE } & \multicolumn{2}{|c|}{ NOMBRE ESTUDIANTE } & CÓDIGO ESTUDIANTIL: \\
\hline & \multicolumn{2}{|c|}{ CORREO ELECTRÓNICO } & CELULAR: \\
\hline & \multicolumn{3}{|c|}{ DATOS DE LA FAMILIA } \\
\hline & \multicolumn{2}{|c|}{ APELLIDO DE LA FAMILIA: } & REPRESENTANTE DE FAMILIA: \\
\hline & BARRIO: & DIRECCIÓN: & TELEFÓNO CELULAR: \\
\hline & \multicolumn{2}{|c|}{ CORREO ELECTRÓNICO: } & \\
\hline \multicolumn{4}{|c|}{$\begin{array}{l}\text { EVALUACIÓN DEL PLAN EDUCATIVO } \\
\text { (Forma de verificar el grado de logro del objetivo general del programa) }\end{array}$} \\
\hline \multicolumn{4}{|c|}{$\begin{array}{l}\text { RESULTADO DE LA INTERVENCIÓN } \\
\text { (Análisis cuantitativo y cualitativo de los resultados programados vs. resultados ejecutados) }\end{array}$} \\
\hline
\end{tabular}

Imagen 5: Instrumento No. 4. Evaluación y Seguimiento de los Resultados

El cuarto y último instrumento utilizado en la etapa 3 se denominó Evaluación y Seguimiento de los Resultados, a través del cual se registró el cumplimiento de los compromisos pactados en las guías anticipatorias, dificultades, barreras y cambios logrados a partir de la comparación del estado inicial y final, después de la intervención educativa realizada. (Imagen $5)$.

\section{Etapas de la TO}

Etapa 1. Valoración del Riesgo Familiary Oral.

Antes de iniciar esta etapa, se indagó la presencia de signos y síntomas en la familia, en relación con contagios por el COVID-19 así como la presencia de otros antecedentes que hubiesen requerido atención odontológica, presencial o de urgencia, como odontalgia, hemorragia o traumatismo dentario. Luego, los estudiantes realizaron un primer encuentro sincrónico con el núcleo familiar de la paciente a través de videollamada por la aplicación WhatsApp. Se diligenció el Instrumento No. 1: Valoración del Riesgo Familiar y Oral.

Con las fotografías intraorales de la paciente y la videollamada se diligenció el instrumento No. 2 CAMBRA. ${ }^{18}$ Para la toma correcta de las fotografías intraorales (en oclusión: lado derecho e izquierdo, de frente, y arcada superior e inferior), se efectuaron las indicaciones necesarias a través del envío de un video a la madre de la paciente, realizado por la Dra. Isabel Olegario, Odontopediatra y docente de la Trinity College, en Dublín, Irlanda y la Dra. Joscarlyn Soto Odontopediatra de Venezuela. Este video surgió como recurso didáctico de apoyo a la TO, dadas las limitaciones a causa de la Pandemia COVID-19. Para el logro de dichas tomas se usó un espejo facial pequeño (Imagen 6-8). 

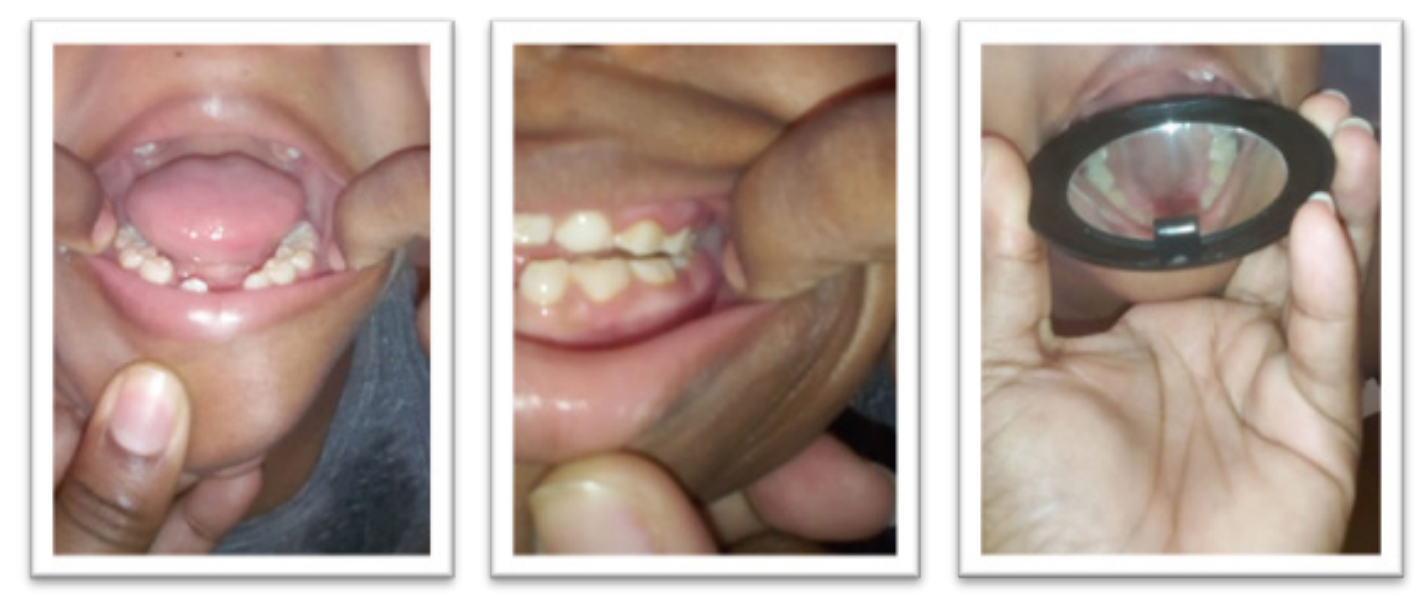

Imagen 6-8. Fotografías obtenidas siguiendo las indicaciones del video para definir del estado de salud oral inicial de la paciente

Posterior al diligenciamiento del instrumento mencionado y a las fotografías obtenidas, se analizaron los factores de riesgo familiar y oral de la paciente. Los estudiantes a cargo elaboraron un plan de guías anticipatorias. Este plan debió ser antes aprobado por el equipo multidisciplinar de docentes, conformado por un especialista en Odontopediatría y un especialista en Salud Pública y Salud Familiar. Esta etapa duró dos semanas en total.

\section{Etapa 2. Orientación para Salud Oral y Familiar}

Una vez elaborado y aprobado el plan de guías anticipatorias (instrumento No. 3) (Imagen No. 9), se dio a conocer el plan a la familia según los factores de riesgo identificados en la paciente y en el núcleo familiar, en un segundo encuentro sincrónico de 15 minutos de duración.

Se establecieron y realizaron 6 encuentros (10 a 15 minutos) con el núcleo familiar, una vez por semana, a través de la aplicación
WhatsApp, de manera sincrónica, desde la semana 3 hasta la semana 8 de la intervención, para la ejecución de 6 guías anticipatorias.

Las guías anticipatorias generadas por cada factor de riesgo fueron enviadas en formato PDF, por WhatsApp, para su lectura desde la asincronía por parte de la familia, una semana antes de cada encuentro sincrónico. Cada encuentro sincrónico por videollamada fue pactado con una duración no mayor de 10 a 15 minutos, periodo de tiempo establecido por el equipo de docentes para estimular la adherencia familiar a la actividad. ${ }^{23}$

En las videollamadas entre los estudiantes y los familiares se aclararon dudas sobre cada guía anticipatoria previamente leída, y se realizó retroalimentación de la información con recomendaciones por parte de los estudiantes. Se propusieron compromisos de cambios de comportamientos viables para favorecer la salud general y oral de la paciente y su familia que se hicieron constar en cada guía. 


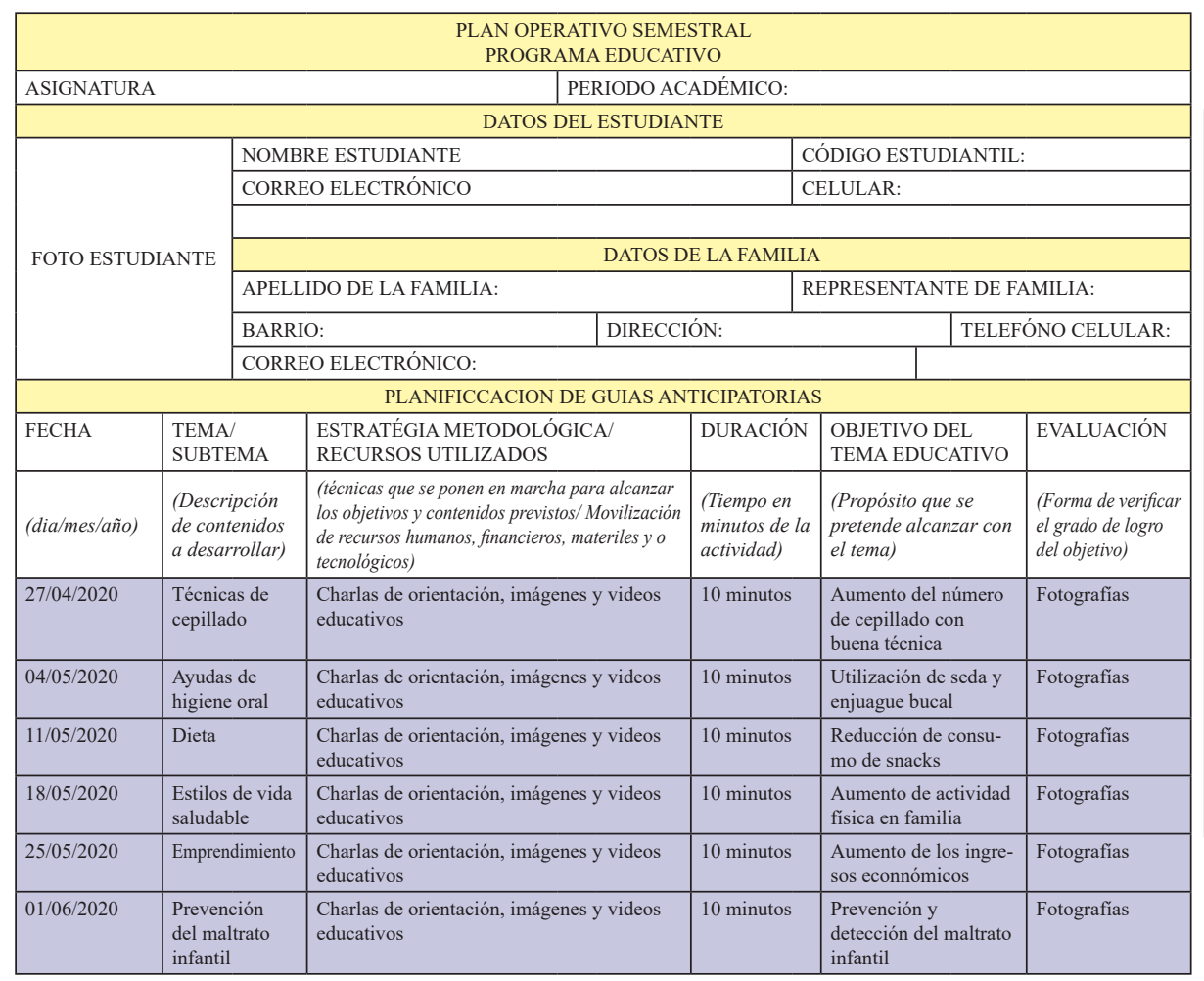

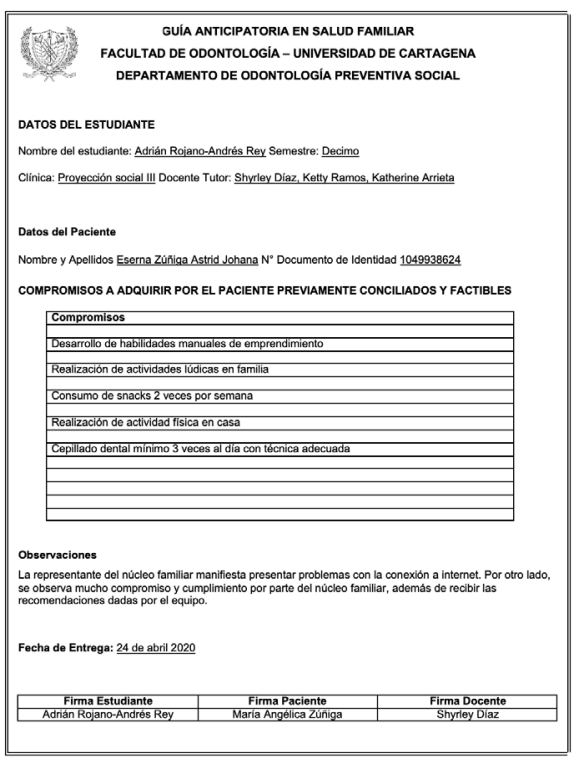

Imagen 9 y 10. Registro del Plan Educativo de las Guías Anticipatorias a realizar.

Tercera etapa. Seguimiento.

Desde la semana 9 hasta la 12 se aplicó el cuarto instrumento (Imagen No. 11), realizándose el seguimiento semanal a través de mensajes de WhatsApp, durante 4 semanas en total. Cada cambio realizado se adjuntaba en el instrumento,

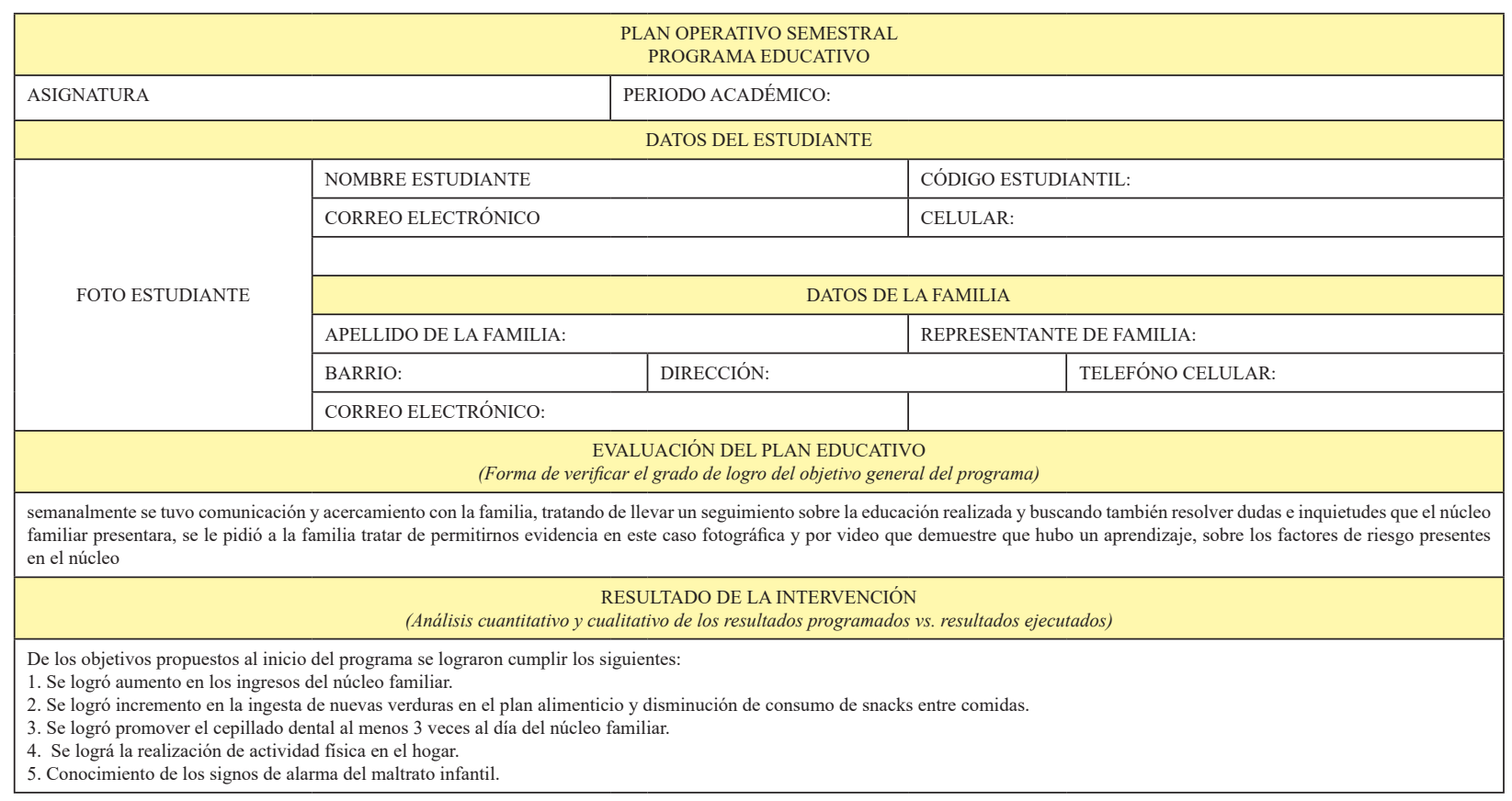

Imagen 11. Instrumento No. 4 Seguimiento y Evaluación de los Resultados diligenciado 
así también información enviada por la madre de la paciente y las actividades de refuerzo realizadas por los estudiantes, como se pueden observar en las imágenes (Imagen No. 12 - 19) obtenidas a partir de capturas de pantalla de video llamadas y conversaciones por WhatsApp.

\section{Descripción del caso}

Se reporta el caso de una paciente femenina de 8 años, diagnosticada con SD (trisomía 21), que presentaba un buen estado de salud médico; a nivel odontológico tenía un estado desfavorable debido a sus limitaciones motrices y la falta de cepillado supervisado por un adulto. La paciente contaba con los servicios de odontología pertenecientes a la institución educativa donde concurría hace un año y en donde cursaba el Prescolar.

La madre de la paciente, de 25 años, era bachiller (13 años cursados). Manifestó que tuvo a la niña a los 17 años. Al momento de realizarse esta intervención, su estado civil era casada, hacía tres años, en segundas nupcias. El marido, de 24 años, hasta ese momento, era técnico mecánico. De esa nueva unión tuvieron un hijo de sexo masculino, de 2 años. Se definió a la familia como familia nuclear que contaba con servicios de salud de carácter público.

Del padre biológico de la paciente, la madre manifestó que no presentaba antecedentes de enfermedades sistémicas, y que no tenía ningún tipo de contacto ni con la niña y ni con ella.

Enla familia, no seregistraronenfermedades o síntomas de COVID 19 en las dos últimas semanas.
Los ingresos familiares mensuales correspondían a $300 \mathrm{mil}$ pesos que representa el $34,1 \%$ de un salario mínimo mensual colombiano vigente. No se registró hacinamiento familiar en el hogar, su vivienda contaba con dos habitaciones (dos personas por habitación). No había antecedentes de SD tanto en la familia materna como paterna biológica.

Se registró en la paciente la presencia a simple vista de biofilm dental, a nivel de las caras vestibulares de las piezas dentarias anteriores superiores e inferiores principalmente. Posterior al cepillado oral, se identificó que la paciente presentaba riesgo alto para caries dental, después de la observación de las fotografías enviadas por la madre y de la aplicación del CAMBRA. Se detectaron 5 lesiones de esmalte (ICDAS 2). Cabe aclarar que se partió de registros fotográficos de baja calidad, lo que dificultó un diagnóstico preciso de las lesiones mencionadas.

El núcleo familiar gozaba de buena salud general; a nivel odontológico mencionaron no presentar problemas de salud oral. Sin embargo, no habían visitado al odontólogo desde hace un año, los cepillados orales de los menores no eran supervisados por un adulto y la técnica usada era un cepillado oral incompleto, sólo en los dientes anteriores. La frecuencia de cepillado oral de todos los miembros de la familia, incluida la de la paciente, era de 1 vez al día.

La familia utilizaba una pasta dental de 1450 ppmF y la paciente tenía una función salival normal, según lo reportado por la madre. El cepillo de dientes de la paciente tenía 6 meses de uso. La familia no contaba con los recursos económicos necesarios 
para el recambio frecuente de cepillo de dientes de todos los miembros. El Instituto junto con la Facultad de Odontología le proveía cepillos de dientes a la paciente para su recambio cada 3 meses, pero con la Pandemia esto se suspendió.

Dentro de los factores de riesgo familiares, se encontró desempleo tanto de la madre como del esposo, y también, estrés, ansiedad e incertidumbre debido a la pandemia por COVID-19.

Se identificó alto consumo de azúcar por parte de la paciente, bajo consumo de verduras (solo consumían tomate y cebolla) de todo el núcleo familiar y ningún de ellos consumía frutas. la paciente consumía más de 3 snacks por día entre comidas (gaseosas, dulces y papas fritas de bolsa). Con relación a la actividad física, se efectuaban aquellas que demandaban poca exigencia, como las tareas en el hogar.

Se diseñó el Plan de Guías anticipatorias en la etapa 2, el cual se dio a conocer a la familia, haciendo énfasis en los factores de riesgo identificados en la paciente y su núcleo familiar

Se propusieron y realizaron las siguientes guías anticipatorias:

- Guía de enseñanza técnica de cepillado: técnica de Stillman para adultos, técnica Fones para la paciente y técnica de Zapatero para el niño con pasta dental de 1100 ppmF, en una planilla de seguimiento, se tenía que registrar la frecuencia de cepillado oral diario, principalmente, la de la paciente. ${ }^{21}$

- Guía de Elementos de higiene oral, seda dental y enjuague oral con fluoruro de sodio al $0,2 \%$.
- Guía de Alimentación saludable: plan alimenticioyseguimiento principalmente de la paciente.

- Guía de Estilos de vida saludable: salud física y manejo del estrés.

- Guía de emprendimiento laboral.

- Guía de Prevención del maltrato infantil (MI) por las condiciones de riesgo que presentaba la paciente (su condición de mujer, abandono del padre biológico y $\mathrm{SD}){ }^{22}$

Las actividades se realizaron a través de charlas educativas con el apoyo de imágenes de videos, folletos y documentos en pdf enviados por medio de la aplicación WhatsApp (Imágenes 12-19).

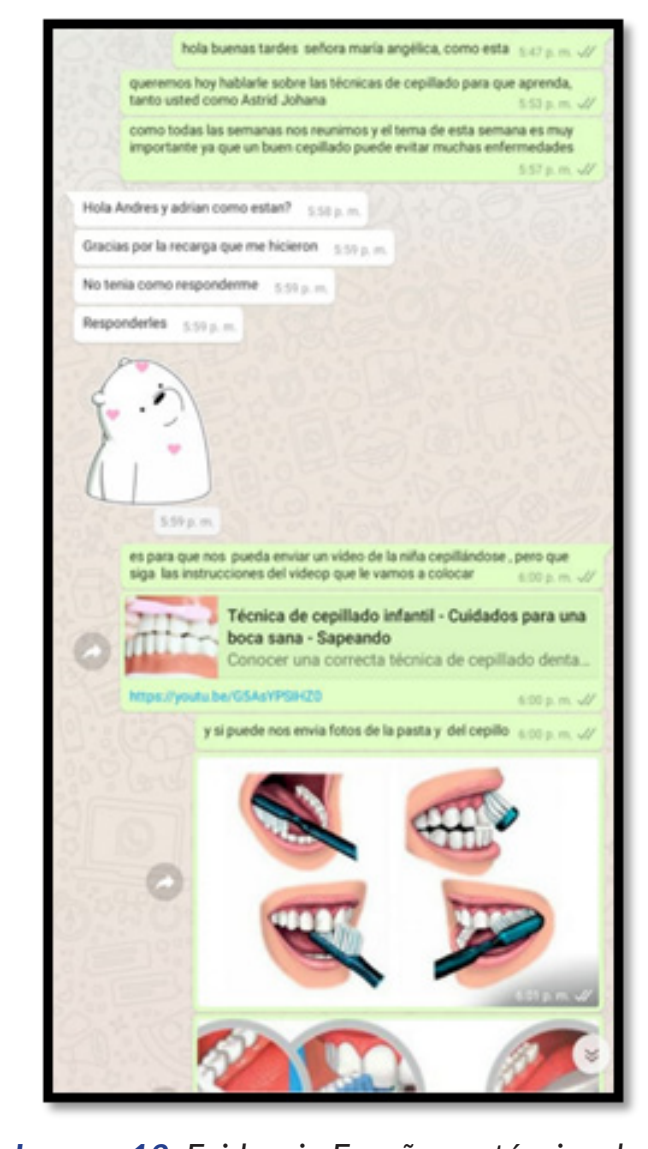

Imagen 12. Evidencia Enseñanza técnica de Cepillado oral por WhatsApp. 


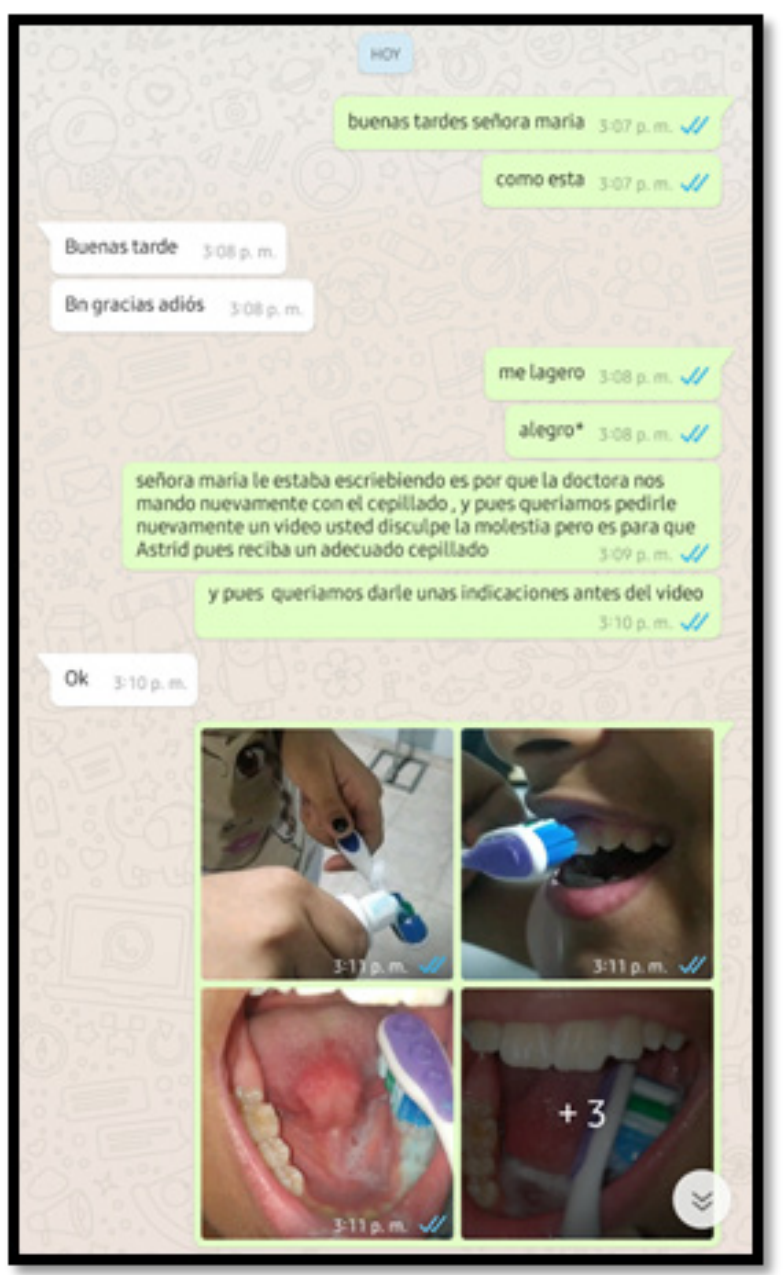

Imagen 13. Evidencia de enseñanza de técnica de cepillado oral por WhatsApp

Posterior al seguimiento realizado durante la etapa, ${ }^{3}$ se logró incrementar la frecuencia del cepillado dental diario de todo el grupo familiar (de 1 vez a 3 veces por día) y el mejoramiento de la técnica de cepillado dentario de la niña (lográndose un cepillado efectivo tanto en el sector anterior como posterior).

Se logró un cepillado supervisado, la madre era quien lo realizaba a los dos niños (el menor ya sabía escupir al iniciar el estudio). Se incorporó uso de seda dental y enjuague oral por lo menos 1 vez al día, manifestando todo

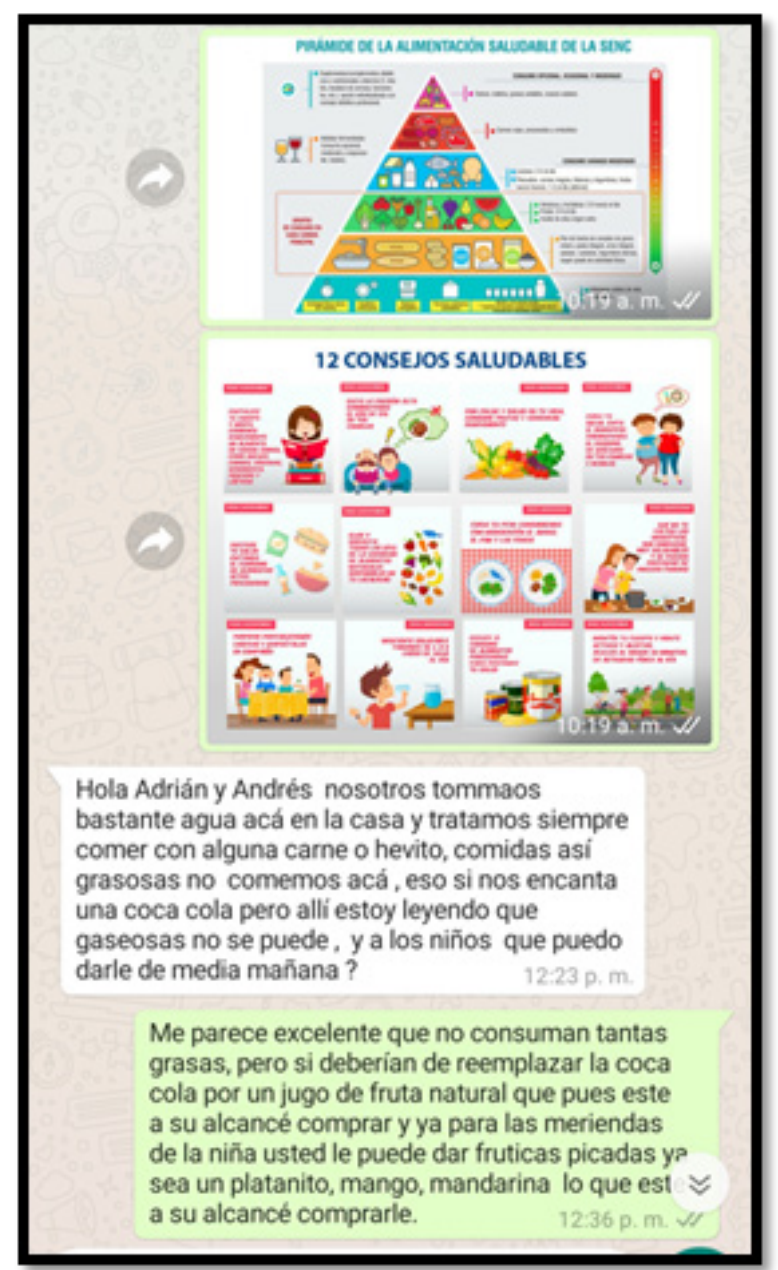

Imagen 14. Enseñanza sobre dieta y estilos de saludables por WhatsApp

el grupo familiar, sentirse cómodos y seguros aplicando las nuevas técnicas de cepillado aprendidas.

El núcleo familiar reportó la ingesta de otras verduras (pepino, zanahoria, habichuelas, remolacha, etc.) a su dieta e incluyó snacks saludables en el plan alimenticio familiar como frutas (mango, papaya y patilla). La familia empezó a realizar actividad física, con una frecuencia de 3 veces a la semana (bailar y caminar dentro de la casa). Se le hizo referencia a posibles estrategias para aumentar los ingresos 


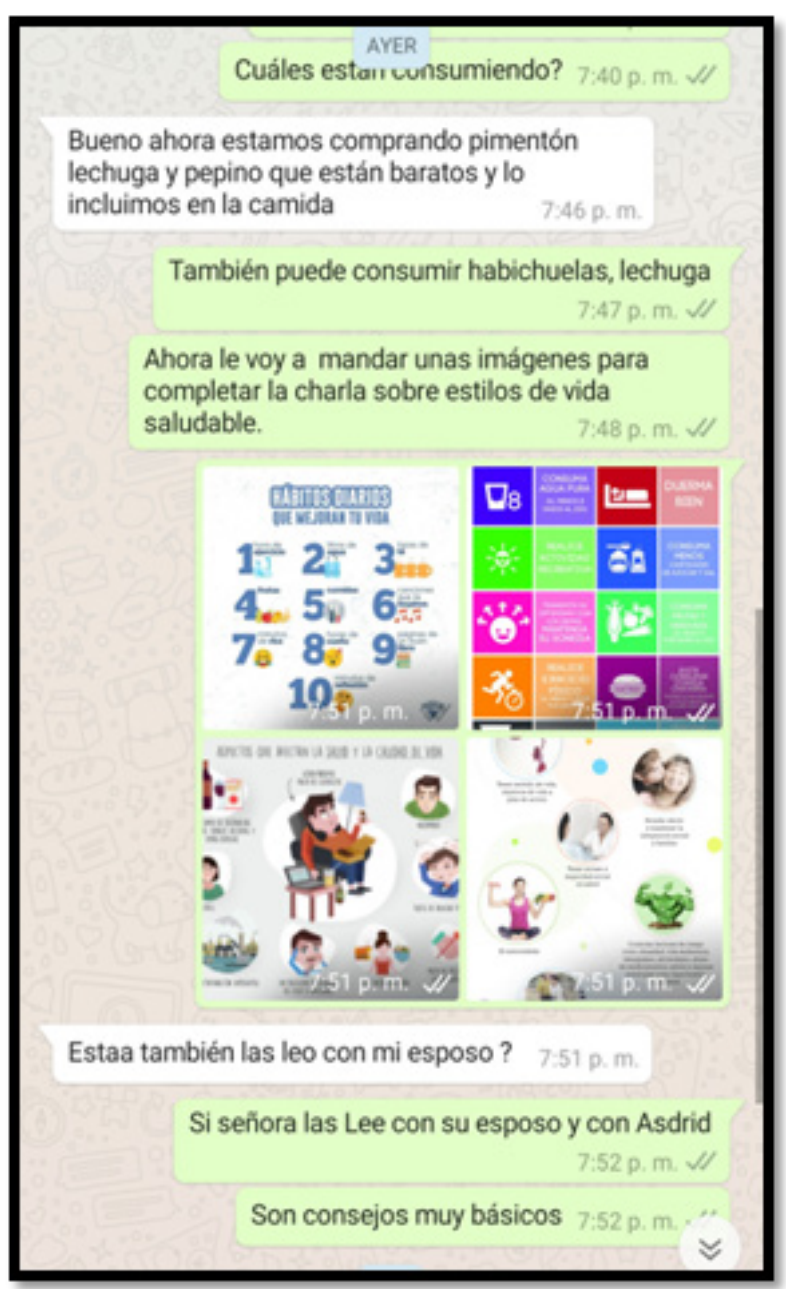

Imagen 15. Enseñanza sobre dieta y estilos de saludables por WhatsApp

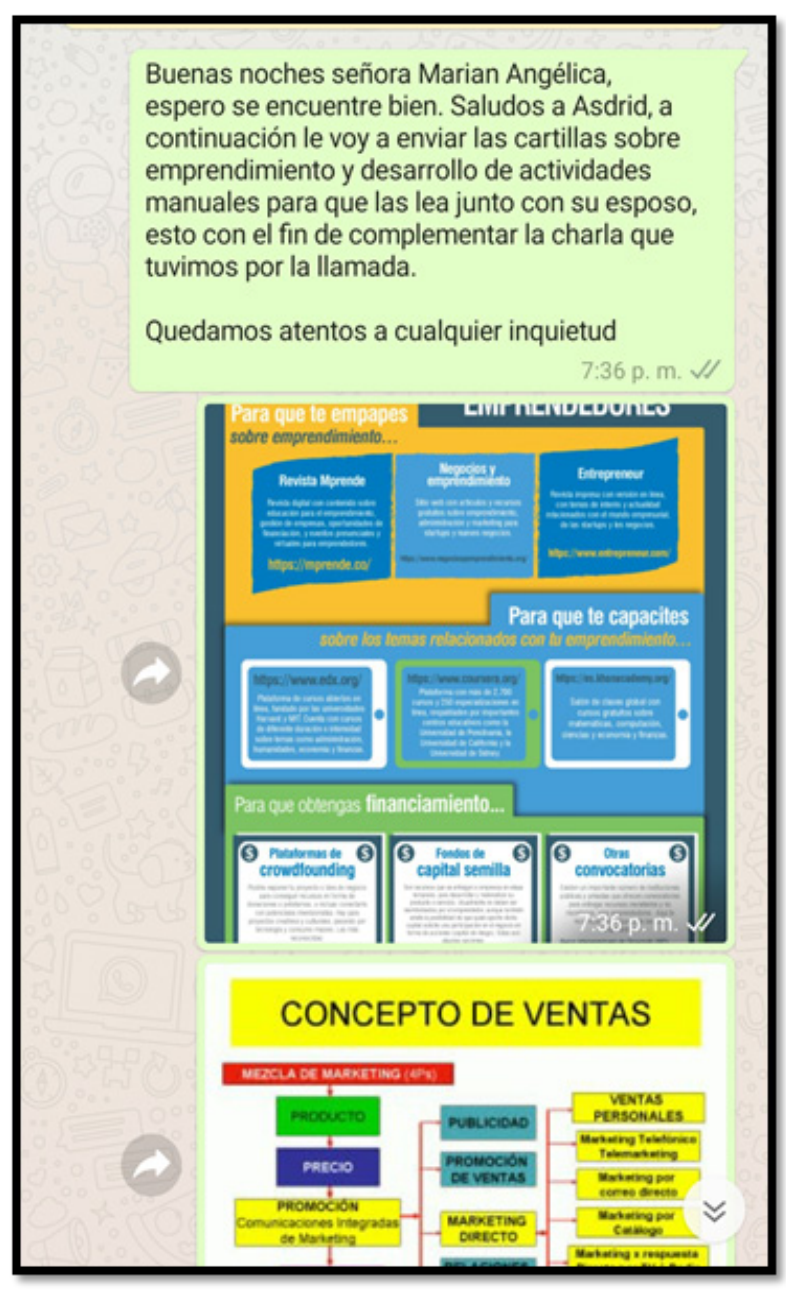

Imagen 16. Educación sobre emprendimiento por WhatsApp económicos, tales como la venta de comida desde el hogar. La madre comentó que empezaron a vender empanadas a partir de la intervención realizada. (Imagen 17 )

Una de las limitaciones que se encontraron fueron fallas en conectividad y disponibilidad de datos de internet, y dificultades con el fluido eléctrico por las condiciones del lugar donde residía el núcleo familiar (instalaciones eléctricas que presentan daños según reportó la familia), lo descripto obligó a reprogramar algunas actividades.

La familia tomó en consideración los indicadores de riesgo para MI. Cuando se realizó la intervención educativa respecto a ese tema, tanto la madre y el padrastro manifestaron haber recibido orientación previa en la Institución y se comprometieron a seguir velando por su salud y bienestar de los niños. 
Hola Andrés y Adrián cómo están. Listo más tardesito me pongo a leerlos con mi esposo y la niña y te cuento cómo nos va. Gracias muy atentos ustedes, estába armando unos fritos que un vecino tiene una fiestecita y le ofreci una bandeja 9:51 a. m.

$\mathrm{Y}$ te mando las fotos que me dijistes oistes estoy muy pendiente $9: 51$ a. $m$

Me parece perfecto señora María Angélica que ya esté haciendo actividades para emprender. 10:01 a. m. V/ Espero las foticos, que tenga buen dia. 10:02 a. m. V/
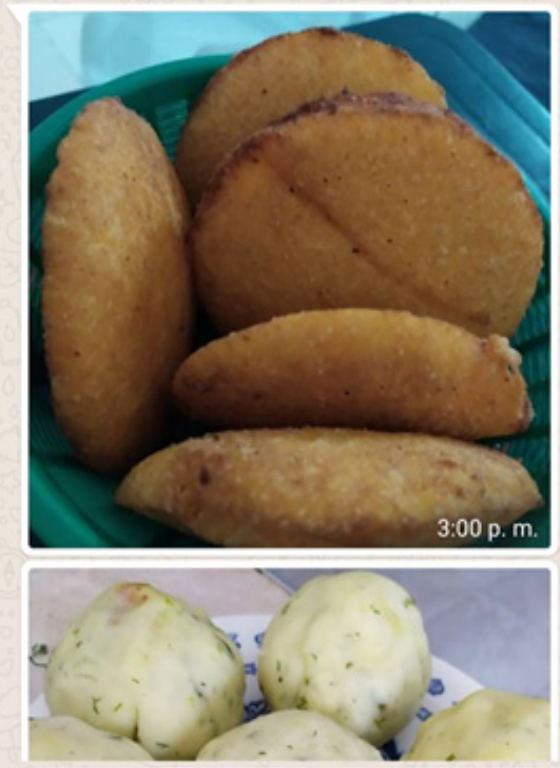

Imagen 17. Resultados obtenidos posterior a la educación sobre el emprendimiento por WhatsApp

\section{Consideraciones éticas}

La madre de la paciente en representación del núcleo familiar brindó el consentimiento informado para la presentación del caso. De igual forma, se obtuvo la autorización del jefe del departamento de Odontología Preventiva y Social de la Facultad de Odontología de la Universidad de Cartagena y del Instituto de Rehabilitación El Rosario, para la realización de la intervención y posterior publicación del
Buenas tardes señora Maria Angélica, nos complace saludarle nuevamente. Como habíamos quedado está mañana le vamos a enviar unas imágenes sobre la campaña de prevención del maltrato infantil $\odot \&$

$4: 00$ p. m. Y/

CAMPAÑA PARA LA PREVENCIÓN DEL MALTRATO Y ABUSO INFANTIL $\odot \& \& \&$

$4: 02$ p. m. VI IQVE ES MALTRATO INFANTIL:

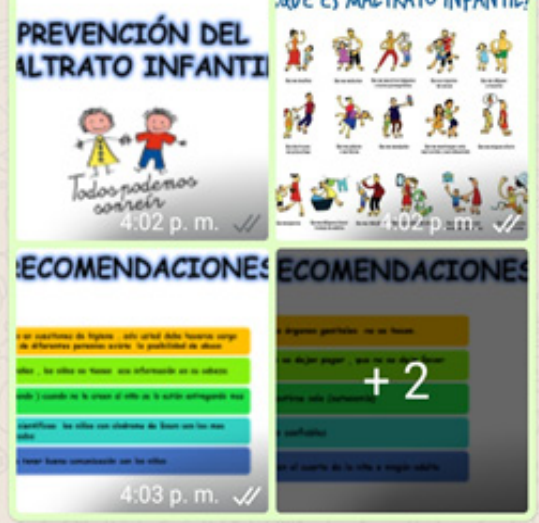

Esas son las imágenes señora María Angélica para que complemente la charla que tuvimos el dia de hoy

4:03 p. m. $\checkmark /$

Quedamos atentos a cualquier duda que tenga $4: 04$ p. m. V/

Hola doctores Andrés y Adrian no les había respondido por qué se me cae la cara de la venganza por no haberles cumplido con el video

Imagen 18. Educación sobre detección y prevención del maltrato infantil por WhatsApp

caso, con el objetivo de procurar una atención odontológica a través de la TO en momentos donde no se puede realizar atención presencial por la Pandemia por COVID 19.

\section{Discusión}

La TO desde la Teleconsulta se convierte en una alternativa de atención oral; se observa un aumento de su popularidadyvalorclínico, especialmente en momentos de crisis 


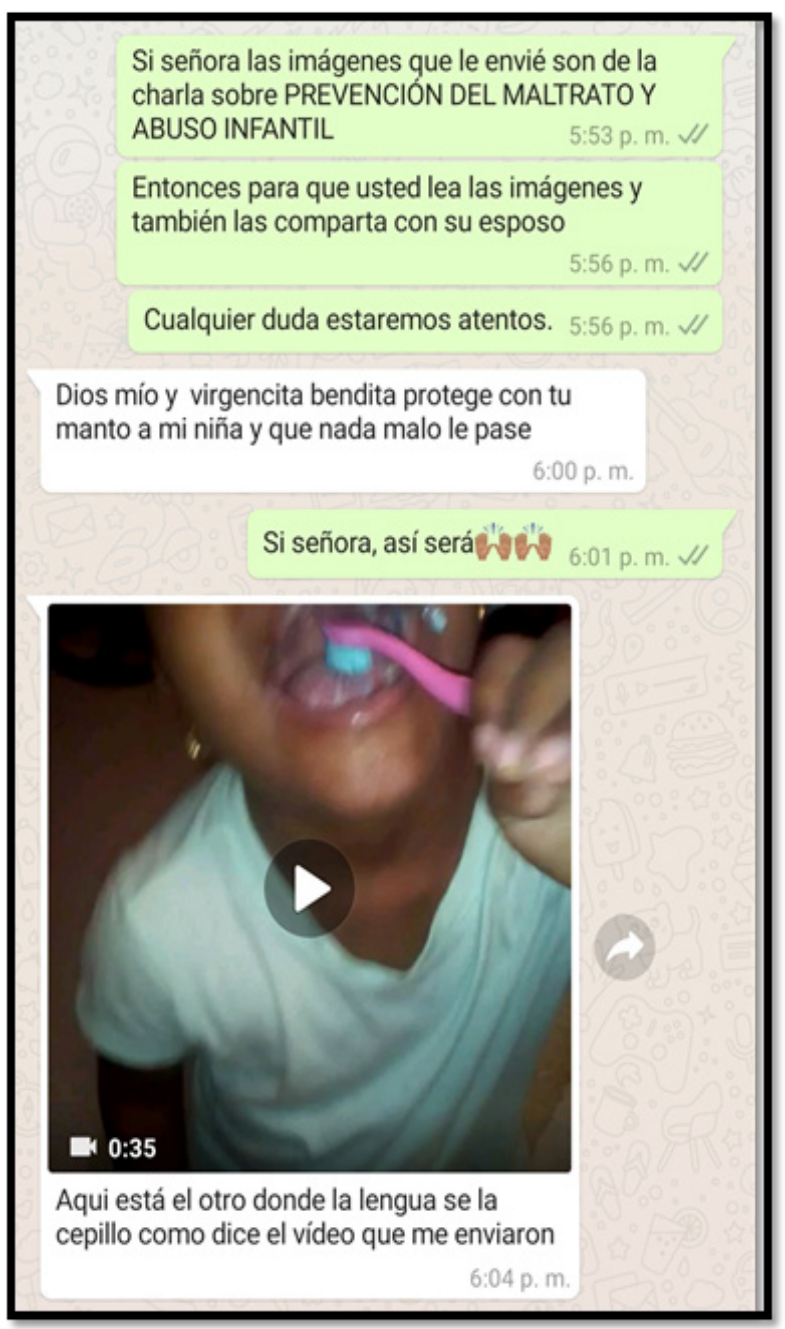

Imagen 19. Evidencia de lo aprendido en las guías anticipatorias de cepillado oral con ayuda de la madre de la paciente por WhatsApp

sanitaria por la Pandemia COVID-19. Esta herramienta virtual en ambientes clínicos controlados ofrece excelentes ventajas para pacientes que presentan dificultades para el acceso a servicios odontológicos, sea por motivos económicos, geográficos, y/o por condiciones de salud, entre otros factores. $^{24}$

Desde la Academia, la TO se convirtió en una herramienta práctica y ágil que permitió continuar con la prestación del servicio de odontología y la adquisición de competencias por parte de los estudiantes bajo estas condiciones sanitarias. ${ }^{8}$

En el caso aquí reportado, la TO propició la motivación y orientación para salud oral de la paciente con síndrome de Down y su familia; se pudo realizar seguimiento del caso, prevención de enfermedades orales, cambios en sus hábitos de higiene oral y estilos de vida, brindando información necesaria a la familia involucrada sobre los factores de riesgo con el objetivo de su disminución y control.

La TO facilita la posible expansión de los servicios odontológicos asegurando el acceso para un mayor número de personas, proponiéndose que a futuro se puedan realizar más actividades lideradas por odontólogos, gracias a la utilización y disponibilidad de equipos de última tecnología, recursos económicos y redes de comunicación más agiles, coincidiendo con lo reportado por Yuen et al. ${ }^{25}$ en 2009 quienes, mediante el uso de la video conferencia, asistieron a pacientes con limitaciones físicas, motoras y adultos mayores.

Cartes et al. ${ }^{26}$ en 2012 plantearon que la TO se puede usar de tres maneras, la primera dirigida a pacientes para la promoción de servicios de salud, la segunda dirigida a la educación continua de profesionales que estén en proceso de especialización y la última dirigida a la prevención de enfermedades en pacientes de grupos especiales. En esta investigación, se usó para realizar actividades de promoción de la salud y prevención de la enfermedad, no sólo a nivel oral sino también a nivel general.

Una de las ventajas de la TO es brindar la posibilidad de realizar conversaciones 
en línea con los pacientes a través de mensajes escritos o de voz para aclarar dudas y brindar sugerencias terapéuticas, y de videos, para una mejor evaluación de las necesidades del pacientey de la descripción de sus problemas. ${ }^{27}$ Lo mencionado le imprime un carácter cálido y cómodo a este tipo de atención, lográndose una mayor colaboración por parte del paciente.

Los elementos utilizados para el desarrollo de las guías anticipatorias como folletos, fotografías y videos facilitaron la posibilidad de realizar cambios de comportamiento de la familia, a través de la aplicación WhatsApp y Google Meet. Esto propició un mayor conocimiento en el manejo de ayudas tecnológicas por parte de los pacientes, y a su vez se convirtió en un recurso valioso para acceder al sistema de salud sin desplazamientos, pero también implicó un gran desafío.

Al no haberse podido realizar una valoración completa de las condiciones orales de la paciente del caso, por la calidad de las fotografías recibidas, se dificultó el diagnóstico del estado bucal y por lo tanto esta situación representó una limitación para la atención. Fernández y Hernandez (2010) ${ }^{28}$ expresaron los beneficios de la Teleconsulta, pero a su vez estos autores definieron las barreras que pueden afectar a esta valiosa forma de atención, como la dificultad para el desarrollo de protocolos de tratamiento y para obtener una información precisa del estado de salud bucal de los pacientes entre otras. ${ }^{29}$ Por tal motivo, en el caso aquí reportado se dedicaron mayores esfuerzos para la orientación sobre higiene oral y dieta.

Por lo expresado, una de las desventajas halladas en el caso expuesto, fue no poder establecer contacto presencial del equipo asistencial, con la paciente y su grupo familiar, que permitiese realizar las maniobras semiológicas necesarias para un diagnóstico preciso y el control de las patologías orales presentes en el grupo familiar.

La creciente disponibilidad de Internet y el desarrollo de dispositivos potentes como teléfonos inteligentes, tabletas y computadoras portátiles facilitarían la mejor implementación de la TO. ${ }^{29,30}$ Otras variables deben ser tenidas en cuenta en su implementación: conectividad, disponibilidad de datos de internet (del paciente) y fluido eléctrico, la ausencia de las variables mencionadas comprometerían el éxito de la atención. ${ }^{31}$ Los estudiantes brindaron, en muchas oportunidades, recargas de datos con fondos propios al celular de la madre de la paciente, para poder realizar la intervención. Dicha implementación no puede ser extrapolada y se requieren otras fuentes de recursos económicos para el desarrollo de la TO como una estrategia de atención sistematizada.

Las restricciones impuestas por el gobierno nacional de Colombia debido a la pandemia por COVID-19, obligaron a la población a buscar nuevas formar de generar ingresos desde el hogar. La motivación lograda a partir de TO por las acciones de los estudiantes, impulsó a la toma de decisiones por parte de los padres para iniciar actividades desde el hogar que aumentaran sus recursos económicos y disminuyeran sus niveles de estrés.

Referente a la modificación de la dieta, la familia incorporó nuevos alimentos que influyeron de manera positiva en 
la reducción del consumo de azúcar, prevención de caries dental y enfermedades crónicas como diabetes y obesidad a largo plazo.

Los niños con necesidades especiales corren un mayor riesgo de MI. Según lo reportado por Nowak ${ }^{27}$ en 2015, esos niños tuvieron 34 veces más probabilidades de ser maltratados. Por ello fue mandatorio abordar dicha temática, para dar a conocer al núcleo familiar, los signos de alarma del MI y su prevención, resaltándose que la TO puede actuar como una herramienta de apoyo en la prevención del $\mathrm{Ml}$ en poblaciones vulnerables.

Al ser comparados los protocolos usados en esta intervención con los publicados por ALOP en junio del $2020^{8}$, se observan algunas similitudes, como realización de un primer acercamiento para indagar si el núcleo familiar necesitaba atención presencial de urgencia (preconsulta virtual). Además, tanto en esta intervención como lo estipulado por la ALOP se definió la importancia de la realización de diagnósticos presuntivos con sus respectivos planes de tratamiento, y el seguimiento (post consulta) de la intervenciones realizadas. Lo anterior confirma la relevancia de la TO aplicada en este trabajo.

Sin embargo, se necesitan más estudios ya que los resultados aquí reportados son insuficientes, se tomaron de una situación particular. No obstante, se ofrece información relevante para ser tenida en cuenta en el futuro, para la implementación de la TO en distintas poblaciones.

\section{Conclusiones}

La TO, a partir de la Teleconsulta constituye una gran oportunidad para la atención en salud oral, especialmente para aquellas poblaciones con condiciones especiales, como la población con SD que requiere seguimiento continuo y permanente.

Este tipo de intervención puede ser una herramienta útil para definir necesidades y así brindar una atención integral con mayor cobertura sin menoscabar la calidad.

\section{Agradecimientos}

Al Instituto de Rehabilitación El Rosario, especialmente a su directora Isabel Lara, quien permitió a los estudiantes y equipo Docente de la Facultad de Odontología de la Universidad de Cartagena realizar atención en salud oral, a partir de la Teleconsulta en Odontología y a las familias beneficiarias del plan de la Institución durante la Pandemia del COVID-19. También, a la Dra. Katherine Arrieta Vergara y Ketty Ramos Martínez por el desarrollo de la estrategia de intervención y diseño de los instrumentos.

\section{Conflictos de interés}

Los autores declaran no tener conflicto de interés.

\section{Referencias bibliográficas}

1. Wang C, Horby PW, Hayden FG, Gao GF. A novel coronavirus outbreak of global health concern. Lancet. 2020; 395(10223):470-473. https://doi:10.1016/S0140-6736(20)30185-9 
2. Thompson R. Pandemic potential of 2019-nCoV. Lancet Infect Dis. 2020; 20(3):280. https://doi:10.1016/ S1473-3099(20)30068-2

3. Harapan H, Itoh N, Yufika A, et al. Coronavirus disease 2019 (COVID-19): A literature review. J Infect Public Health.2020; 13(5):667-673. https://doi:10.1016/j.jiph.2020.03.019

4. Dave M, Seoudi N, Coulthard P. Urgent dental care for patients during the COVID-19 pandemic. Lancet.2020; 395(10232):1257. https://doi: 10.1016/S0140-6736 (20) 30806-0.

5. Balaji SM. COVID-19-Future of dentistry. Indian J Dent Res. 2020; 31(2):167-168. https://doi:10.4103/ ijdr.IJDR_347_20

6. Peng X, Xu X, Li Y, Cheng L, Zhou X, Ren B. Transmission routes of 2019-nCoV and controls in dental practice. Int J Oral Sci. 2020; 12(1):9. https://doi:10.1038/s41368-020-0075-9

7. Resolución 2654 de 2019. Por la cual se establecen disposiciones para la telesalud y parámetros para la práctica de la Telemedicina en Colombia. Ministerio de Salud y Protección Social; 2019.

8. Revista de Odontopediatría Latinoamericana E de trabajo multidisciplinario de la. Teleodontología: Aplicación a la Odontopediatría durante la pandemia COVID-19. Rev. Odontopediatr. Latinoam. [Internet];10(2). Disponible en: https://revistaodontopediatria.org/index.php/alop/article/view/192

9. Khan SA, Omar H. Teledentistry in practice: literature review. Telemed J E Health.2013; 19(7):565-7. https://doi: 10.1089/tmj.2012.0200.

10. Telles-Araujo GT, Caminha RDG, Kallás MS, Santos PSDS. Teledentistry support in COVID-19 oral care. Clinics. 2020; 75: e2030. https://doi:10.6061/clinics/2020/e2030

11. Machado RA, de Souza NL, Oliveira RM, Martelli Júnior H, Bonan PRF. Social media and telemedicine for oral diagnosis and counselling in the COVID-19 era. Oral Oncol. 2020;105: 104685.https://doi:10.1016/j. oraloncology.2020.104685

12. Weijerman ME et al. Prevalencia, características neonatales y mortalidad durante el primer año del síndrome de down: un estudio nacional. J. Pediatrics. 2008; (152): 15-19. Disponible en: https://www.down21. org/revista-virtual/440-revista-virtual-2008/revista-virtual-marzo-2008/resumen-marzo-2008/1645epidemiologia-del-sindrome-de-down.html

13. Nazer J, Cifuentes L. Estudio epidemiológico global del síndrome de Down. Rev Chil Pediatr. 2011; 82(2): 105-112. Disponible en: http://dx.doi.org/10.4067/S0370-41062011000200004

14. Díaz-Cuéllar S, Yokoyama-Rebollar E, Del CastilloRuiz V. Genómica del síndrome de Down. Acta Pediatr Mex. 2016; 37(5):289-296. https://doi.org/10.18233/APM37No5pp289-296

15. Rodríguez-Guerrero K, Clavería-Clark RA, Peña-Sisto M. Algunas características clínico epidemiológicas del síndrome de Down y su repercusión en la cavidad oral. MEDISAN. 2015: 19(10): 1272-1282. Disponible en: http://scielo.sld.cu/scielo.php?script=sci_arttext\&pid=S1029-30192015001000013

16. Tirado L, Díaz S, Ramos K. Salud oral en escolares con síndrome de Down en Cartagena (Colombia). Rev Clin Med Fam. 2015; 8(2) 110-118. https://dx.doi.org/10.4321/S1699-695X2015000200004

17. Resolución $N^{\circ} 008430$. Por la cual se establecen las normas científicas, técnicas y administrativas para la investigación en salud. Bogotá: Ministerio de Salud; 1993.

18. Featherstone JDB, Domejean-Orliaguet S, Jenson L, Wolff M, Young DA. Caries riskassessment in practiceforage 6 throughadult. J CalifDentAssoc. 2007;35(10):703-7, 710-3

19. Hoeckelman, R. Primary pediatriccares,Pp 196-230. CV Mosby Co, St, Louis,Washintong, Toronto, 1987.

20. Rakel, R. Family Medicine: 541-564. 2nd ed.

21. Martínez M. C, Galvis D. A, Builes Ángela P, García D. A, Cañas L. T, Arango M. I. The use of fluoride dentifrices in children: conceptual bases in a confusing context: a topic review. Rev Fac Odontol Univ Antioq. 2017; 29(1), 187-210. https://doi.org/10.17533/udea.rfo.v29n1a10

22. World Health Organization. (2009). Prevención del maltrato infantil: qué hacer, y cómo obtener evidencias. Organización Mundial de la Salud. https://apps.who.int/iris/handle/10665/44228

23. Rahman, N., Nathwani, S., \& Kandiah, T. Teledentistry from a patient perspective during the coronavirus pandemic. British dental journal. 2020; 229 (3) 1-4. doi: 10.1038/s41415-020-1919-6

24. Birnbach JM. The future of teledentistry. J Calif Dent Assoc. 2000; 28(2):141-3.

25. Yuen HK, Pope C. Oral home telecare for adults with tetraplegia: a feasibility study. Spec Care Dentist. 2009; 29(5): 204-209. https://doi.org/10.1111/j.1754-4505.2009.00094.x

26. Cartes R, Bustos A. Teleodontología: Conceptos, experiencias y proyecciones. Odontoestomatología. 2012; 14(20): 17-25. Disponible: <http://www.scielo.edu.uy/scielo.php?script=sci_ arttext\&pid=S168893392012000200003\&lng=es\&nrm=iso >. ISSN 1688-9339. 
27. Nowak CB. Recognition and prevention of child abuse in the child with disability. Am J Med Genet C Semin Med Genet. 2015; 169(4):293-301. doi:10.1002/ajmg.c.31458.

28. Fernández J, Hernández M. Telemedicina: futuro o presente. Rev haban cienc méd. 2010; 9(1). Disponible en: http://scielo.sld.cu/scielo.php?script=sci_arttext\&pid=S1729519X2010000100017\&Ing=es.

29. Giraudeau N, Inquimbert C, Delafoy R, et al. Teledentistry, new oral care tool for prisoners. International Journal of PrisonerHealth. 2017; 13(2):124-134 https://doi: 10.1108 / IJPH-04-2016-0011.

30. Baig M.M., GholamHosseini H., Connolly M.J. Mobile healthcare applications: System design review, critical issues and challenges. Australas. Phys. Eng. Sci. Med. 2015; (38):23-38. https://doi: 10.1007/s13246-0140315-4.

31. Márquez JR. Teleconsulta en la pandemia por Coronavirus: desafíos para la telemedicina pos-COVID-19. Rev Col Gastroenterol. 2020; 35(1): 5-16. https://doi.org/10.22516/25007440.543.

Recibido: 28/04/2021

Aceptado: 04/11/2021

Correspondencia: Adrián Rojano-Rodríguez, correo: arojanor@unicartagena.edu.co 